Int. J. Dev. Biol. 52: 759-768 (2008)

doi: $10.1387 /$ ijdb.082581ss

\title{
Oyster sperm bindin is a combinatorial fucose lectin with remarkable intra-species diversity
}

\author{
STEVAN A. SPRINGER ${ }^{1}$, GARY W. MOY², DANIEL S. FRIEND ${ }^{3}$, WILLIE J. SWANSON ${ }^{4}$ \\ and VICTOR D. VACQUIER ${ }^{2}$ \\ ${ }^{1}$ Department of Biology, University of Washington, Seattle, Washington, ${ }^{2}$ Scripps Institution of Oceanography, University of California \\ San Diego, La Jolla, California, ${ }^{3}$ Brigham and Women's Hospital, Harvard Medical School, Boston, Massachusetts and \\ ${ }^{4}$ Department of Genome Sciences, University of Washington, Seattle WA, USA
}

\begin{abstract}
Sperm of the oyster, Crassostrea gigas, have ring-shaped acrosomes that, after exocytosis, bind the sperm to the egg vitelline layer. Isolated acrosomal rings contain proteins of various sizes: 35-, 48-, 63-, 75- and 88-kDa. These proteins, called bindins, have identical 24-residue signal peptides and conserved 97 -residue $\mathrm{N}$-terminal sequences, and they differ in mass because of the presence of between 1 and 5 tandemly repeated 134-residue fucose-binding lectin (F-lectin) domains. Southern blots suggest that oyster bindin is a single copy gene, but F-lectin repeat number and sequence are variable within and between individuals. Eight residues in the F-lectin fucose-binding groove are subject to positive diversifying selection, indicating a history of adaptive evolution at the lectin's active site. There is one intron in the middle of each F-lectin repeat, and recombination in this intron creates many combinations of repeat halves. Alternative splicing creates many additional size and sequence variants of the repeat array. Males contain fulllength bindin cDNAs of all 5 possible sizes, but only one or two protein mass forms exist in each individual. Sequence analysis indicates that recombination and alternate splicing create hundreds, possibly thousands, of different bindin sequences in $C$. gigas. The extreme within-species sequence variation in the F-lectin sequence of oyster bindin is a novel finding; most male gameterecognition proteins are much less variable. In experimental conditions oyster eggs have poor polyspermy blocks, and bindin diversity could be an evolutionary response by sperm to match egg receptors that have diversified to avoid being fertilized by multiple sperm.
\end{abstract}

KEY WORDS: sperm-egg interaction, gamete recognition, invertebrate fertilization, positive selection, molecular evolution, alternative splicing, recombination

\section{Introduction}

Marine invertebrates, echinoderms, mollusks, tunicates, annelids and others, are ideal organisms for fertilization studies because many release their sperm and eggs freely into the water column and their gametes are easy to collect and experimentally manipulate. Because these animals are free spawning, there are relatively few behavioral barriers to mating between species. Closely related species are often reproductively isolated by species-specific fertilization patterns, at equivalent gamete concentrations the eggs of species $A$ are more easily fertilized with sperm of species $A$ than with sperm of species $B$. This specificity is a result of molecular recognition, the binding of sperm proteins and cognate egg surface receptors. These types of molecular recog- nition events are a general feature of sperm egg interaction and can be encoded in any of the five steps of fertilization: 1) chemoattraction of sperm in response to egg-released molecules, 2) binding of sperm to egg extracellular investments, 3) induction of sperm acrosomal vesicle exocytosis by egg surface molecules, 4) penetration of the egg investments by acrosomal proteins, and 5) fusion of sperm and egg plasma membranes (Vacquier, 1998). Within species cognate pairs of fertilization proteins must evolve together because recognition failures during fertilization can cause reproductive incompatibility. It was therefore initially surprising to find that many fertilization proteins evolve rapidly

Abbreviations used in this paper: $\mathrm{AR}$, acrosomal ring; $\mathrm{VE}$, vitelline envelope.

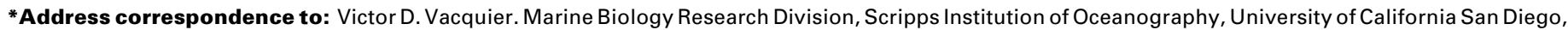
La Jolla, CA 92093-0202. Tel: +1-858-534-4803. Fax: +1-858-534-7313. email: vvacquier@ucsd.edu
} 
(Swanson and Vacquier, 2002). This rapid divergence could alter patterns of mate-choice within species and ultimately cause the evolution of sperm-egg incompatibility between species. These are important areas of inquiry because the simple nature of gamete recognition systems may allow us to answer questions about the process of speciation and adaptation that are not tractable in more complex systems. (Palumbi 1992).

Molecular recognition events at fertilization have been intensively studied in sea urchins and abalone, and studies of other externally fertilizing marine invertebrates are now taking form. In sea urchins, sperm egg recognition is controlled by bindin, a protein released from the acrosomal vesicle (Vacquier, et al., 1995; see article by Zigler in this issue), and EBR1, a large egg surface glycoprotein (Kamei and Glabe, 2003). Bindins from tropical sea urchins of the genus Echinometra mediate the species-specific attachment and fusion of sperm to egg (Glabe and Vacquier, 1977, Landry et al., 2003, McCartney and Lessios, 2004, Metz and Palumbi, 1996, Metz et al., 1994, Palumbi and Metz, 1991). Sea urchin species each have their own particular bindin sequence, and bindin is sometimes polymorphic within species (Biermann, 1998, Metz et al., 1998a, Zigler and Lessios, 2003a, Zigler and Lessios, 2003b, Zigler and Lessios 2004, Zigler et al., 2005). In abalone (Haliotis), sperm gain entry to the egg by releasing an acrosomal protein (lysin) that makes a hole in the egg vitelline envelope (VE) by a species-specific, non-enzymatic mechanism (Kresge et al., 2001). Lysin binds to VERL the VE receptor for lysin (Galindo et al., 2003, Swanson and Vacquier, $1997,1998)$. Another abalone sperm acrosomal protein (sp18) fuses the sperm and egg membranes by binding an unknown receptor (Swanson and Vacquier, 1995a, 1995b). The sequences of both of these abalone sperm proteins are subject to strong divergent selection between species, but both are nearly mono-

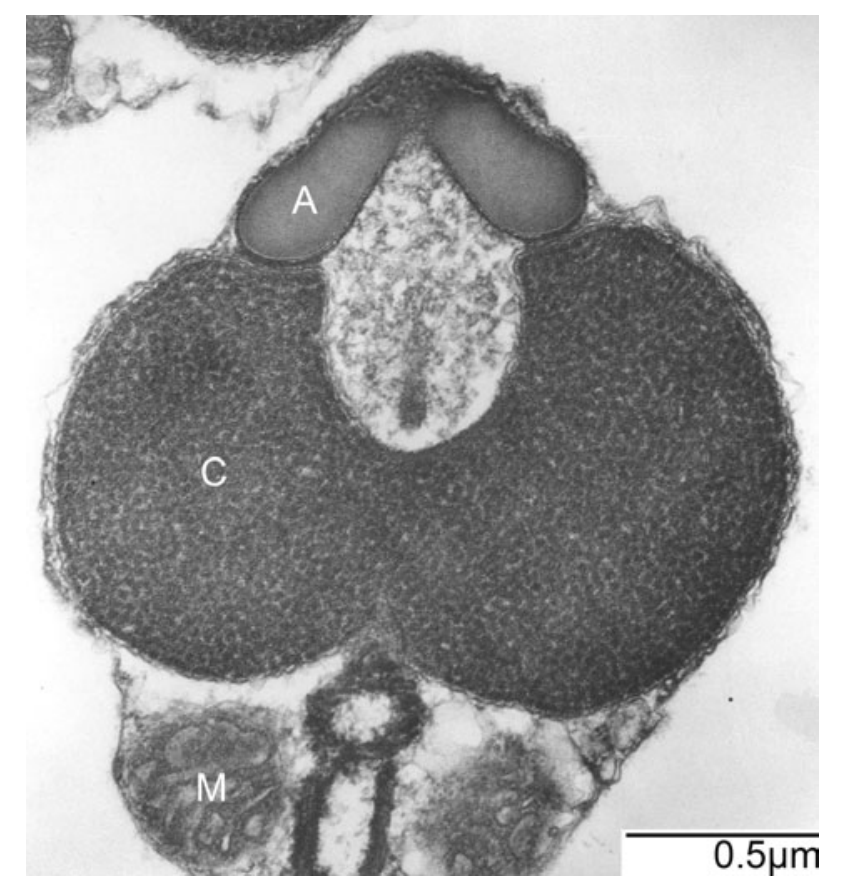

Fig. 1. Transmission electron micrograph, longitudinal thin section, of the head of a Crassostrea gigas spermatozoon. Note the disk-shaped acrosome vesicle $(A)$, the chromatin $(C)$ and the mitochondrion (M). morphic within species (Metz et al., 1998b). In Mytilus blue mussels, sperm acrosomal lysins dissolve the mussel egg VE (Takagi et al., 1994). One of these proteins, Lysin-M7, evolves rapidly and is subject to positive selection between species (Riginos and McDonald, 2003) and within M. galloprovincialis (Riginos et al., 2006, Springer and Crespi, 2007). Although there are species-specific sequence differences in these sea urchin, abalone and mussel sperm proteins, the number of different sequences within a species is small. One abalone species has a duplicated lysin gene (Clark et al., 2007), and Mytilus has three related lysin genes (Takagi et al., 1994), but genes coding for sperm acrosomal proteins are typically single copy with alleles that can be distinguished by PCR.

In contrast, sperm bindin of the commercial oyster Crassostrea gigas has remarkable sequence variation within individuals and within the species. The use of the word "bindin" for both sea urchin and oyster sperm acrosomal proteins relates only to their role in adhering sperm to eggs, there is no ancestral relationship between the bindin genes of these two groups. Oyster bindin is subject to combinatorial mechanisms, recombination and alternative splicing, that create remarkable protein sequence variation. Within C. gigas, there are hundreds, potentially thousands, of different sequences of the bindin protein. In this article, we review our work on the diversity of oyster sperm bindin and its role in fertilization.

\section{Oyster fertilization}

Crassostrea gigas do not have testes as distinct organs. Spermatocyte stem cells proliferate and differentiate in response to warm water and ample nutrition, and when the shells are opened the mass of sperm can be scraped away from the internal organs and dispersed in seawater. The ultrastructure of fertilization is conserved across many of the bivalve species that have been studied (Hylander and Summers, 1977, Togo and Morisawa, 1999). Transmission electron micrographs of oocytes show that a vitelline envelope (VE) adheres to the oocyte plasma membrane. Microvilli extend from the oocyte surface through the VE, their tips covered with fibrous material. Oyster sperm have a round head containing a ring-shaped acrosomal vesicle about 1 $\mu \mathrm{m}$ in diameter (Fig. 1). When the acrosome undergoes exocytosis, a ring of adhesive bindin protein is exposed that attaches the sperm to the tips of egg microvilli protruding through the VE. The finger-like acrosomal process extends by actin polymerization through the ring of bindin, and the newly exposed sperm plasma membrane covering the acrosomal process then fuses with the oocyte membrane.

\section{Isolation of acrosomal rings of bindin}

The methods presented here are a summary of those described by Brandriff et al. (1978) and Moy et al. (2008). Sperm are obtained and washed into filtered seawater (containing $10 \mathrm{mM}$ MES, pH 6.0; MES-SW) by sedimentation at 1,000 xg (15 min) and resuspension with a spatula in fresh 25-100 vol MES-SW (all procedures are at $4^{\circ} \mathrm{C}$ ). The last wash contains $0.2 \mathrm{mg} / \mathrm{ml}$ soybean trypsin inhibitor (SBTI) and $5 \mathrm{mM}$ benzamidine to block serine proteases. Between 1 and $5 \mathrm{ml}$ of packed, washed sperm are resuspended in lysing medium (10 $\mathrm{mM}$ sodium acetate, 10 


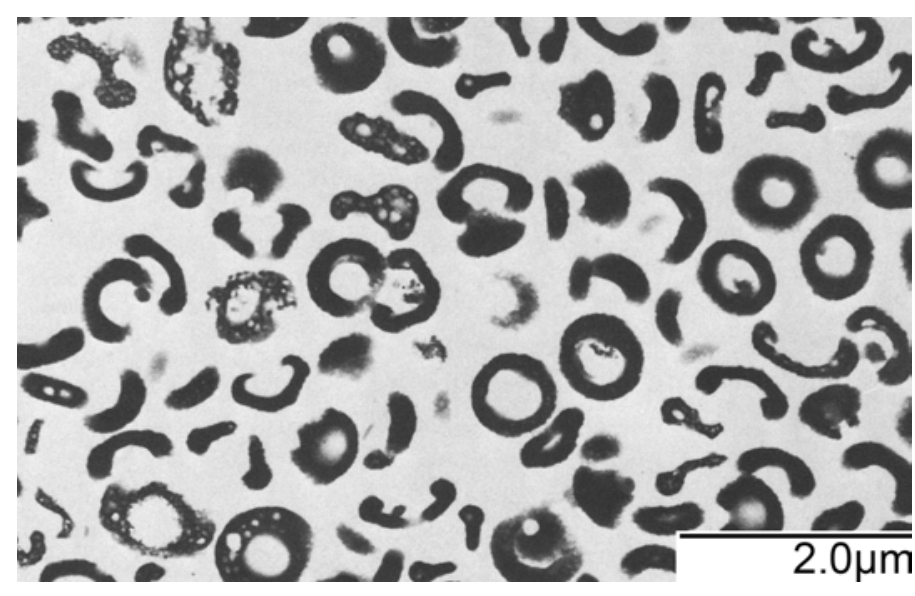

Fig. 2. Transmission electron micrograph of a thin section of isolated acrosomal rings from C. gigas sperm. Figure from Brandriffet al., 1978.

$\mathrm{mM}$ benzamidine, $0.2 \mathrm{mg} / \mathrm{ml} \mathrm{SBTI}, 10 \mathrm{mM}$ MES, $\mathrm{pH} \mathrm{6.0)} \mathrm{by} \mathrm{hand}$ stirring with a spatula. Then, while vigorously stirring, a $10 \% \mathrm{w} / \mathrm{v}$ solution of sodium lauryl sarkosyl is added to a final concentration of $0.5 \%$. The sperm suspension gels when the detergent releases the nuclear DNA. The DNA gel is degraded by homogenization in a Waring Blender, or by a glass ball homogenizer. The low viscosity homogenate is then centrifuged $26,000 \mathrm{xg}$ for $60 \mathrm{~min}$. The pellet of acrosomal rings (AR) is resuspended in fresh lysing buffer with $0.5 \%$ sarkosyl and rehomogenized with a $10 \mathrm{ml}$ glass ball tissue grinder. To solubilize the molluscan "sperm nuclear basic protein" of 34-kDa (Eirin-Lopez et al., 2006) away from the insoluble AR, the AR pellet is extracted with 25-100 vol lysing buffer containing $0.6 \mathrm{M} \mathrm{KCl}$ without sarkosyl. The isolated $A R$ are then resedimented and resuspended in fresh lysing buffer without sarkosyl and phase contrast microscopy performed at $\sim 1200 \mathrm{x}$ magnification. The isolated AR appear as rings when viewed by phase contrast or transmission electron microscopy (Fig. 2; The preparation for electron microscopy is described in Brandriff et al., 1978).

Early work showed that isolated AR agglutinate unfertilized oocytes (Brandriff et al., 1978). Digestion of oocytes with trypsin, followed by inhibition of the enzyme with SBTI, and removal of the digested oocytes, yielded a glycopeptide digest of the egg surface. Preincubation of isolated AR with this digest destroyed the ability of the AR to agglutinate oocytes, suggesting that the AR acted in a lectin-like manner by binding to carbohydrate residues on oocyte surface glycoproteins. Chemical analysis indicated that the AR were as much as $16 \%$ carbohydrate by dry weight, indicating that oyster bindin was probably itself a glycoprotein (Brandriff et al., 1978).

\section{Mass variation in oyster bindin}

SDS-polyacrylamide gel electrophoresis of the proteins contained in isolated AR yielded surprising results. From any one male, AR are composed primarily of one or two Coomassie blue staining bands of 35-, 48-, 63-, 75-, or 88-kDa, but which of these proteins are present depends on the individual (Fig. 3). The most common are the 48- and 63-kDa proteins that had been previously found in oyster sperm AR by Brandriff etal. (1978). The least common are the $35-$ and $88-\mathrm{kDa}$ proteins. Bands of the $63-\mathrm{kDa}$ protein were excised from gels and inoculated into rabbits for antibody production by standard methods. The rabbit antiserum, and preimmune serum, was stored at $-70^{\circ} \mathrm{C}$ as cell-free plasma. To show that the differences in relative molecular mass are not due to protease degradation during $A R$ isolation, sperm from individual males were solubilized in $10 \%$ SDS at $100^{\circ} \mathrm{C}$. Five bands migrating at 35-, 48-, 63-, 75- and 88-kDa reacted with the antibindin serum on western blots (Fig. 3). These antibindin reacting proteins differed from each other by approximately $12-$ 15-kDa. Preimmune serum did not react with any oyster sperm protein.

\section{cDNA sequences of oyster sperm bindin}

Tens of milligrams of AR were isolated and the Coomassie blue staining bindin bands electro-transferred to PVDF membrane for amino acid sequencing. Three of these five AR proteins (48-, 63and $88-\mathrm{kDa}$ ) were sequenced and found to have identical $\mathrm{N}$ terminal amino acid sequences. Internal amino acid sequences of the 48-kDa band were obtained and oligonucleotide primers were designed. cDNA was synthesized from total RNA extracted from spermatogenic tissue of individual male oysters. Full-length bindin sequences were generated by 5' and 3' RACE, and primers were then designed to amplify the entire coding region of bindin. Standard PCR reactions were performed and the PCR products cloned. A total of 39 full-length bindin cDNA sequences were obtained from 16 males from 5 oyster culture facilities in: Oregon State (OR), Washington State (WA), Japan (JP), Brazil (BZ) and New Zealand (NZ) (Moy et al., 2008).

Sequencing these clones showed that oyster bindin contains

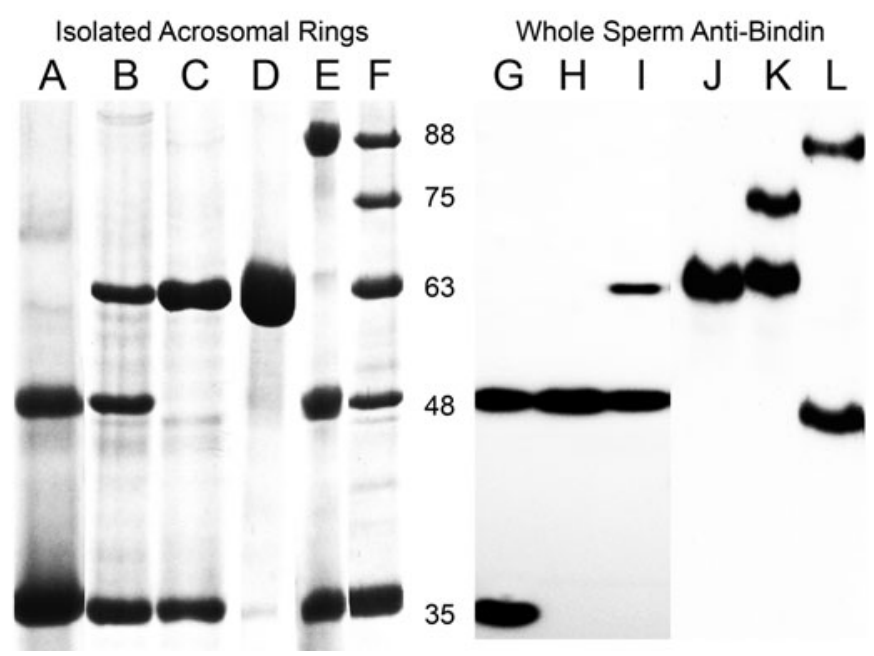

Fig. 3. Oyster bindin protein mass variation. Lanes A-F show a Coomassie blue stained $10 \%$ SDS-PAGE gel of isolated acrosomal rings. Each lane is a different individual male oyster with one or two different bindin alleles. The lanes are contaminated with the 34-kDa sperm major basic protein (Eirin-Lopez et al., 2006), which can be extracted with 0.6 $\mathrm{M} \mathrm{KCl}$ from the acrosomal rings as shown in lane $D$. Lane $F$ is acrosomal rings pooled from many males showing the 35-, 48-, 63-, 75- and 88-kDa bindins. Lanes G-L are Western immunoblots of whole sperm from individual males. The antibody was made against the 63-kDa bindin band purified by SDS-PAGE of isolated acrosomal rings. Preimmune serum from the same rabbit did not react with any oyster sperm protein. $50 \mu \mathrm{g}$ protein per lane. Figure adapted from Moy et al., 2008. 
a fucose-recognizing lectin domain (F-lectin) of 134 amino acids. The oyster sperm F-lectin is $45 \%$ similar to the F-lectin fold consensus sequence in the protein domain database (smart00607). Bindin proteins differ from each other because of the number of F-lectin domains they contain: mature bindin proteins with one F-lectin domain are $35-\mathrm{kDa}$, those with two

TABLE 1

\section{SIZE AND SEQUENCE VARIABILITY OF BINDIN cDNAS BY SAMPLING LOCATION}

\begin{tabular}{|c|c|c|c|}
\hline Population & Individual & Repeats & cDNA \\
\hline $\begin{array}{l}\text { Santa Catarina, Brazil } \\
28: 21: 27 S \text { 48:52:27W }\end{array}$ & BR1 & $\begin{array}{l}4 \\
1\end{array}$ & $\begin{array}{r}5^{\prime}-B Y-D Y-D Y-D Z-3 ' \\
5 '-B Z-3^{\prime}\end{array}$ \\
\hline \multirow{2}{*}{$\begin{array}{c}\text { Aomori, Japan } \\
\text { 40:49:36N } \\
\text { 140:45:38E }\end{array}$} & JP1 & 4 & 5'-CY-DY-DY-EZ-3' \\
\hline & JP2 & $\begin{array}{l}5 \\
5 \\
2\end{array}$ & $\begin{array}{r}\text { 5'-AX-DY-EY-EY-EZ-3' } \\
\text { 5'-CY-CY-EY-EY-EZ-3' } \\
\text { 5'-AX-EZ-3' }\end{array}$ \\
\hline \multirow{3}{*}{$\begin{array}{c}\text { Hokkaido, Japan } \\
\text { 43:01:29N } \\
\text { 144:50:33E }\end{array}$} & JP3 & 3 & 5'-BY-BY-EZ-3' \\
\hline & & 1 & 5'-BZ-3' \\
\hline & $\mathrm{JP} 4$ & $\begin{array}{l}3 \\
2 \\
1 \\
1\end{array}$ & $\begin{array}{r}\text { 5'-BY-BY-DZ-3' } \\
5 \text { '-BY-CZ-3' } \\
5 \text { '-BZ-3' } \\
5^{\prime}-C Z-3^{\prime}\end{array}$ \\
\hline \multirow{3}{*}{$\begin{array}{c}\text { Nelson, New Zealand } \\
41: 18: 32 \mathrm{~S} \\
173: 11: 12 \mathrm{E}\end{array}$} & $\mathrm{NZ1}$ & $\begin{array}{l}3 \\
1\end{array}$ & $\begin{array}{r}\text { 5'-BY-BY-EZ-3' } \\
5 \text { '-BZ-3' }\end{array}$ \\
\hline & NZ2 & $\begin{array}{l}3 \\
3 \\
2 \\
1\end{array}$ & $\begin{array}{r}\text { 5'-CY-BY-EZ-3' } \\
5^{\prime}-C Y-B Y-E Z-3^{\prime} \\
5^{\prime}-A X-E Z-3^{\prime} \\
5^{\prime}-E Z-3^{\prime}\end{array}$ \\
\hline & NZ4 & $\begin{array}{l}3 \\
3 \\
3\end{array}$ & $\begin{array}{l}\text { 5'-AX-CY-EZ-3' } \\
\text { 5'-BY-BY-EZ-3' } \\
\text { 5'-BY-CY-EZ-3' }\end{array}$ \\
\hline \multirow{3}{*}{$\begin{array}{c}\text { Newport, Oregon } \\
\text { USA } \\
\text { 44:37:25N } \\
124: 02: 46 \mathrm{~W}\end{array}$} & OR1 & 4 & $\overline{5 '-A X-C Y-E Y-E Z-3 '}$ \\
\hline & OR3 & $\begin{array}{l}4 \\
2\end{array}$ & $\begin{array}{r}\text { 5'-CY-DY-DY-EZ-3' } \\
\text { 5'-AX-EZ-3' }\end{array}$ \\
\hline & OR6 & 4 & 5'-CY-EY-EY-EZ-3' \\
\hline \multirow[t]{4}{*}{$\begin{array}{c}\text { Willapa Bay, } \\
\text { Washington USA } \\
\text { 46:29:46N } \\
\text { 124:01:59W }\end{array}$} & WA3 & $\begin{array}{l}4 \\
3 \\
2 \\
1\end{array}$ & $\begin{array}{r}\text { 5'-AX-CY-DY-EZ-3' } \\
\text { 5'-DY-EY-EZ-3' } \\
\text { 5'-DY-EZ-3' } \\
\text { 5'-AZ-3' }\end{array}$ \\
\hline & WA4 & $\begin{array}{l}5 \\
5 \\
4 \\
3 \\
2 \\
1\end{array}$ & $\begin{array}{r}\text { 5'AX-CY-DY-DY-EZ-3' } \\
\text { 5'-AY-DY-DY-EY-CZ-3' } \\
\text { 5'-CY-DY-DY-EZ-3' } \\
\text { 5'-CY-DY-EZ-3' } \\
\text { 5'-DY-EZ-3' } \\
5^{\prime}-E Z-3^{\prime}\end{array}$ \\
\hline & WA12 & $\begin{array}{l}3 \\
2 \\
1\end{array}$ & $\begin{array}{r}5^{\prime}-A X-C Y-C Z-3^{\prime} \\
5^{\prime}-A Y-D Z-3^{\prime} \\
5^{\prime}-C Z-3^{\prime}\end{array}$ \\
\hline & WA27 & 3 & 5'-AX-CY-CZ-3' \\
\hline
\end{tabular}

cDNA abbreviations: each set of two letters is one repeat, letters designate the sequence variability shown in Fig. 7. The intron where recombination occurs is between each two contiguous letters. Dashes separate repeats at the locations of alternative splicing

\section{TABLE 2}

PATTERNS OF ALTERNATE SPLICING AT THE BOUNDARIES OF F-LECTIN REPEATS

\begin{tabular}{ccccccc} 
& A & B & C & D & E & \\
\hline $\mathbf{5}^{\prime}$ & $13(4.74)$ & $11(6.20)$ & $10(8.02)$ & $3(7.65)$ & $2(12.4)$ & 39 \\
$\mathbf{X}$ & $0(1.21)$ & $0(1.59)$ & $6(2.06)$ & $1(1.96)$ & $3(3.18)$ & 10 \\
$\mathbf{Y}$ & $0(7.05)$ & $6(9.21)$ & $6(11.9)$ & $17(11.4)$ & $29(18.4)$ & 58 \\
& 13 & 17 & 22 & 21 & 34 & 107 \\
\hline
\end{tabular}

Pairwise associations at the boundaries of F-lectin repeats. $5^{\prime}$ is the $\mathrm{N}$-terminal unique region. Clade definitions are shown in Fig. 7. Clade $Z$ is always associated with the $3^{\prime}$ UTR. Contingency table values are: observed (expected).

Chi-squared test (chi-square $=61.0, \mathrm{df}=8, \mathrm{p}<0.001$ ) and Fisher's exact contingency table test $(\mathrm{p}<0.001$, sum of unusual tables $\mathrm{p}=0.000$ ) indicate that repeats are not connected to one another at random. domains are 48-kDa, three are 63-kDa, four are 75-kDa and five are $88-\mathrm{kDa}$ (the calculated protein mass is $86,944 \mathrm{Da}$ ). The bindin sequences are deposited in GenBank under accession numbers EF219425-EF219429. The full-length sequence of a bindin cDNA with five tandem F-lectin domains is in Fig. 4. From amino- to carboxyl-terminus there is a 24 amino acid signal sequence (M1 to G24), followed by a mature N-terminus from A25 to Q122. BLAST searches show that the $\mathrm{N}$-terminus sequence has no relationship to any known protein. In Fig. 4, the first F-lectin domain is from $\mathrm{V} 123$ to $\mathrm{N} 260$, other figures are numbered relative to the start of each F-Lectin repeat. Internal F-lectin repeats are separated by a spacer peptide of PGAK or PGAKGK. The last residue of the last F-lectin repeat (in Fig. 4, G808) is immediately followed by the stop codon. There is a 3'UTR of approximately 250 bases before the polyA+ tail. Presumably, this sperm lectin recognizes an egg surface glycoprotein receptor with exposed fucose residues and that this molecular affinity bonds the sperm to the egg.

\section{Oyster bindin is a single copy gene}

Genomic DNA was isolated from seven diploid Oregon male Crassostrea gigas sperm cells. The DNA was digested with three restriction enzymes that do not cut within the cDNA. Southern blots were prepared by standard methods and hybridized with a radiophosphate-labeled probe to either the F-lectin repeat, or the 3'UTR (Moy et al., 2008). In all males, the 3'UTR probe hybridized to a maximum of two DNA fragments per individual, suggesting that bindin is a single copy gene (Fig. 5). The probe of the F-lectin repeat, hybridized to 4-10 DNA fragments. Of the seven diploid individuals no two had the identical pattern of hybridization with the repeat probe. This suggests that there is an intron within the F-lectin repeat containing restriction sites recognized by these three enzymes (Fig. 5). To be certain that gene rearrangement did not occur in the bindin gene in sperm, Southern blots were done on sperm, gill and mantle DNA from one male. The patterns of hybridization with these probes on these three DNAs were identical, showing that rearrangement of the bindin gene in spermatocytes does not occur (data not shown). We tentatively conclude that oyster bindin is a single copy gene containing 1 to 5 tandem $\mathrm{F}$-lectin repeats in the genomic DNA.

\section{Alternative splicing and size variation of oyster bindin cDNAs}

cDNA was synthesized from total RNA isolated from the spermatogenic cells of a single male. PCR with a forward primer located at the extreme 5' terminus and a reverse primer in the 3'UTR amplified the entire bindin cDNA. PCR products were TOPO cloned and minipreps made from individual colonies. Restriction analysis of these plasmids showed that each individual male contains multiple bindin cDNAs with between 1 and 5 F-lectin repeats (Fig. 6). The sequences of these plasmids confirm that a full bindin cDNA is present in each. The number of Flectin repeats in each genomic bindin allele is unknown, but sequence variation suggests one way for cDNAs with different numbers of repeats to be produced is by alternative splicing of the primary transcript (Table 1; repeats are labeled according to Fig. 7 ). In the 39 full-length cDNAs sequences that we have obtained 


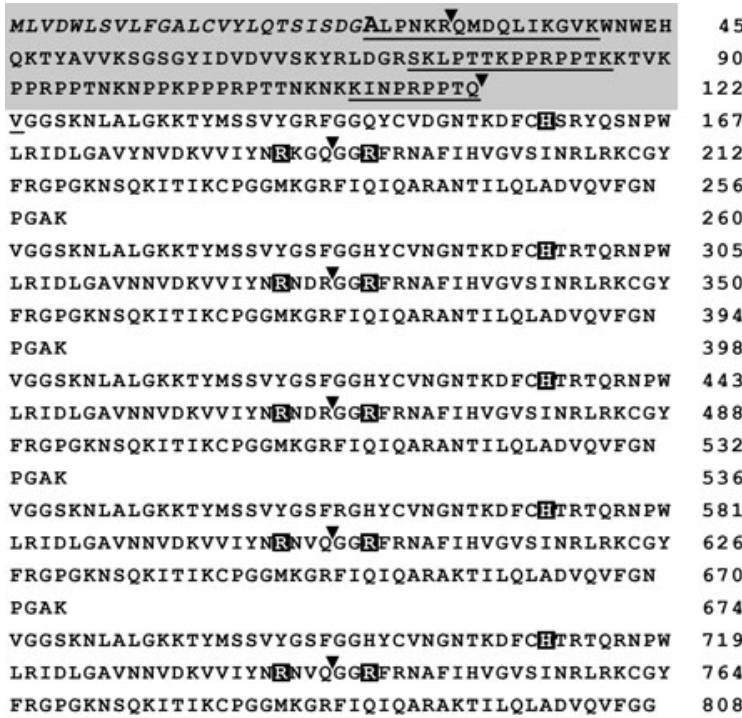

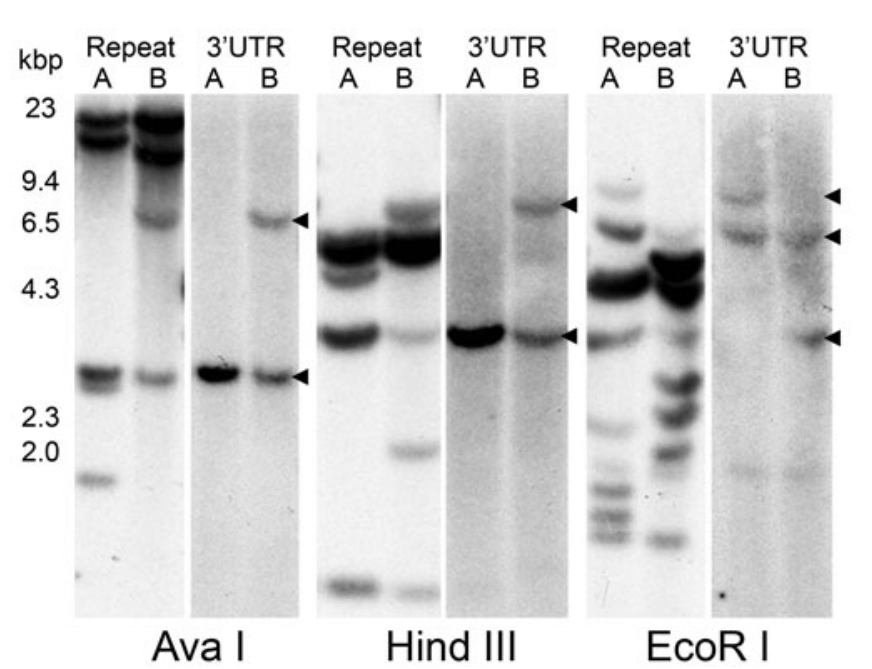

Fig. 4 (Left). Amino acid sequence of a $\boldsymbol{C}$. gigas sperm bindin with five F-lectin repeats. Underlined sequences were obtained by protein sequencing. The grey box encloses the $\mathrm{N}$-terminal region of the protein. There is a signal sequence of 24 residues (italics). The mature $\mathrm{N}$-terminus extends from residue A25 to residue Q122. F-lectin repeats begin with VGG and are separated by the linker sequence PGAK. The single H and two $R$ residues in each repeat that are diagnostic for fucose binding are in black boxes. Arrows show the positions of introns. Each repeat has one intron between repeat residues 67-68 where recombination of repeat halves occurs. The calculated molecular mass of the mature protein is 86,944 Da.

Fig. 5 (Right). Southern blots of sperm DNA of two males (A and B) digested with three restriction enzymes (Ava I, Hind III, EcoR I) that do not cut within the bindin cDNA. Blots were hybridized with radiophosphate labeled probes to either a full length F-lectin repeat (Repeat), or to the C-terminal half of the last repeat and 3'UTR (3'UTR). When cut with Ava I, Hind III, and EcoR I, the 3'UTR probe gave a maximum of two bands of hybridization. These data suggest that oyster bindin is a single copy gene. Of seven diploid males, no two had identical hybridization patterns to the repeat probe; some males reacted with as many as 10 DNA fragments. Figure from Moy et al., 2008.

from 16 males collected in 5 worldwide locations we have found 9 cDNAs with one repeat, 7 with two repeats, 12 with three repeats, 7 with four repeats and 4 with five repeats. Patterns of alternative splicing between repeats are shown in Tables 1 and 2.

\section{Recombination and sequence variation in F-lectin re- peats}

In our collection of $107 \mathrm{~F}$-lectin repeats there are 41 with unique amino acid sequences. The diversity of repeat sequences is remarkable, using identical sequencing techniques we found only five amino acid substitutions (out of 4,315 amino acid residues) in

\section{TABLE 3}

\section{PATTERNS OF RECOMBINATION AT THE F-LECTIN REPEAT INTRON}

\begin{tabular}{|c|c|c|c|c|}
\hline & $\mathbf{x}$ & $\mathbf{Y}$ & z & \\
\hline A & $10(1.21)$ & $2(7.05)$ & $1(4.74)$ & 13 \\
\hline B & $0(1.59)$ & $13(9.21)$ & $4(6.20)$ & 17 \\
\hline C & $0(2.06)$ & $16(11.9)$ & $6(8.02)$ & 22 \\
\hline D & $0(1.96)$ & $18(11.4)$ & $3(7.65)$ & 21 \\
\hline \multirow[t]{2}{*}{$E$} & $0(3.18)$ & $9(18.4)$ & $25(12.4)$ & 34 \\
\hline & 10 & 58 & 39 & 107 \\
\hline
\end{tabular}

Pairwise associations between the $5^{\prime}$ and 3 ' halves of the F-lectin repeats. Clade definitions are shown in Fig. 7. Contingency table values are: observed (expected).

Chi-squared test (chi-square $=107.0, \mathrm{df}=8, \mathrm{p}<0.001$ ) and Fisher's exact contingency table test $(p<0.001$, sum of unusual tables $p=0.000)$ indicate that repeat-halves are not connected to one another at random. the $\mathrm{N}$-terminal region of these 39 full-length bindins. An alignment of the $41 \mathrm{~F}$-lectin repeat sequences was analyzed for evidence of recombination (Kosakovsky et al., 2006). Within each repeat there is one site, between residues $67-68$, where recombination occurs (Fig. 7). Sequence from genomic DNA showed that there is a large phase 0 intron at exactly this position in each repeat. Dividing the repeats at the recombination site shows that in the 107 repeats there are 24 unique $\mathrm{N}$-terminal halves; these sequences group into 5 clades (A-E) representing 5 commonly

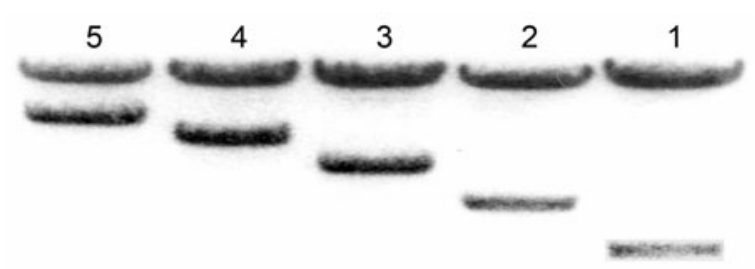

Fig. 6. Five bindin cDNAs from a single individual. Total RNA was isolated from spermatogenic cells from one male, cDNA was synthesized and a $P C R$ reaction performed with primers that amplify the entire bindin sequence. The PCR product was cloned into PCR-XL-TOPO (Invitrogen) and individual clones were randomly picked and grown in liquid medium. Isolated plasmid DNA was cut with EcoR I, and the fragments separated on agarose gels. The ethidium bromide stained bands show the vector at $3.5 \mathrm{~kb}$ and the inserts representing full-length cDNAs with from 1-5 Flectin repeats. Each male contains a pool of alternatively spliced mRNA, with bindins containing from 1 to 5 F-lectin repeats. Figure from supplementary data in Moy et al., 2008. 

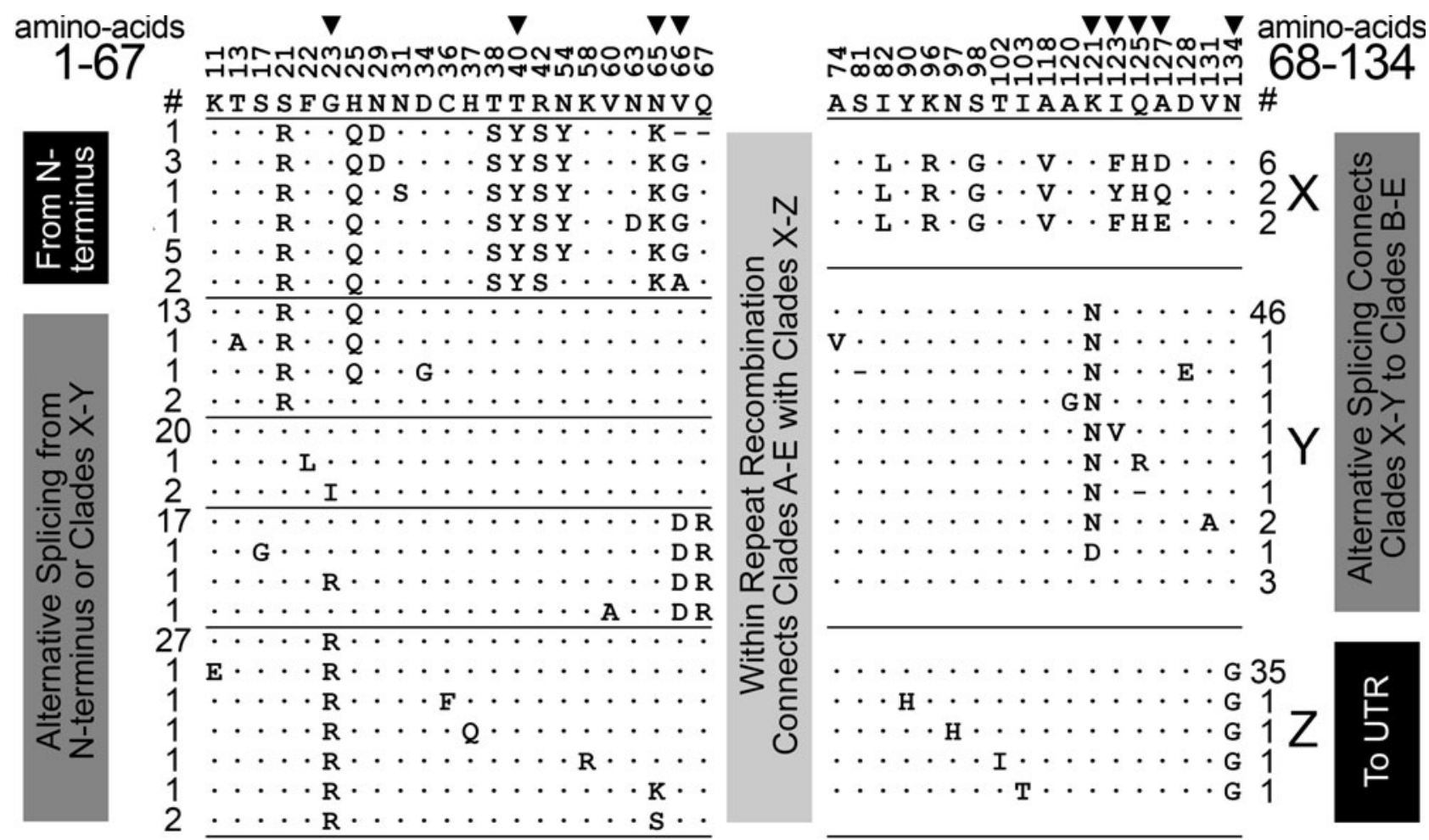

Fig. 7. Sequence variation in 107 F-lectin repeats from 39 full-length bindins. We observed 41 different repeat sequences. The amino acid positions of all variable sites (numbered relative to the beginning of each repeat) are above the consensus sequence. Arrows show the nine positively selected sites (dN/dS >1). Sequences are split in half at the light grey box between sites 67 and 68 . Recombination in an intron at this position creates pair-wise combinations of the 24 unique $N$-terminal and 18 unique $C$-terminal repeat halves (Table 3). Numbers in the left and right columns show the number of times a particular half-repeat was sampled. The N-terminal halves (1-67) form five clades (A-E) and the C-terminal halves (68-134) form three clades $(X-Z)$ based on major frequency alleles and their mutational variants. Dark grey boxes indicate the alternative splice combinations at the repeat boundaries, black boxes show combinations where splicing was not observed (Table 2).

sampled alleles and their mutational variants. There are 18 unique C-terminal halves of repeats that organize into 3 clades (Fig. 7). Patterns of recombination between the $\mathrm{N}$ and $\mathrm{C}$-terminal halves of repeats are shown in Table 3.

\section{Positive selection in oyster bindin}

Maximum likelihood methods of detecting selection (Yang, 1997) find four positions in the $\mathrm{N}$-terminal half repeat (residues 23 , 40,65 and 66 , estimated $\mathrm{dN} / \mathrm{dS}=6.0$ ), and five positions in the Cterminal half repeat (residues 121, 123, 125, 127, and 134, estimated $\mathrm{dN} / \mathrm{dS}=5.0$ ) that have been subject to positive selection (Table 4). A dN/dS of 1.0 indicates neutral evolution, amino acid substitutions occur at the same rate $(\mathrm{dN})$ as silent substitutions (dS), a dN/dS ratio greater than 1.0 indicates positive selection (amino acid changes accumulate more rapidly than silent changes) a ratio below one indicates purifying selection. The sequences of bindin F-lectin repeats were threaded onto the crystal structure of the Streptococcus pneumoniae F-lectin protein (Lambert et al., 2002, Boraston et al., 2006). Eight of the nine positively selected positions cluster in the fucose-binding region of the structure (Fig. 8). These eight residues surround the three residues (H37, $\mathrm{R} 64$ and $\mathrm{R} 70$ ) that are diagnostic for fucose binding (Bianchet et al., 2002). Polymorphic sites, (those with substitutions observed in more than one of our bindin sequences) and singleton sites (those with substitutions observed only once in our data set) do not spatially cluster on the structure (Fig.9). Positive selection indicates a history of adaptive amino acid changes in bindin. Clustering of these adaptive changes around the fucose-binding site suggests that the selective advantage may have come from their effect on the affinity between sperm

\section{TABLE 4}

\section{LIKELIHOOD RATIO TEST OF POSITIVE SELECTION IN CRASSOSTREA BINDIN REPEATS}

\begin{tabular}{|c|c|c|c|c|c|c|c|c|}
\hline Codons & $n$ & S & $\mathrm{dN} / \mathrm{dS}$ & $\begin{array}{c}2 \Delta \mathrm{L} \\
\mathrm{M} 3 \mid \mathrm{M} 0\end{array}$ & $\begin{array}{c}2 \Delta \mathrm{L} \\
\mathrm{M} 8 \mid \mathrm{M} 7\end{array}$ & $\begin{array}{c}2 \Delta \mathrm{L} \\
\mathrm{M} 8 \mid \mathrm{M} 8 \mathrm{a}\end{array}$ & $\begin{array}{l}\text { Parameter } \\
\text { Estimates } \\
\text { M8(beta\& } \omega)\end{array}$ & $\begin{array}{l}\text { Positively } \\
\text { Selected Sites } \\
\text { M8(NEB) }\end{array}$ \\
\hline $1-67$ & 24 & 0.63 & 1.00 & 8.1 & $7.0^{*}$ & $6.7^{\star \star}$ & $\begin{array}{l}\omega=6.02, \\
\text { p1 }=0.071, \\
B(99.00,51.11)\end{array}$ & $\begin{array}{l}0230.9858^{\star} \\
0400.5125 \\
0650.9672^{\star} \\
0660.7429\end{array}$ \\
\hline 68-134 & 18 & 0.55 & 0.76 & $14.6^{*}$ & $6.8^{*}$ & $6.8^{* *}$ & $\begin{array}{l}\boldsymbol{\omega}=\mathbf{5 . 0 4}, \\
\mathbf{p} 1=\mathbf{0 . 1 2 9}, \\
B(46.98,99.00)\end{array}$ & $\begin{array}{l}1210.9978^{\star *} \\
1230.9869^{\star} \\
1250.8589 \\
1270.9947^{\star *} \\
1340.8323\end{array}$ \\
\hline
\end{tabular}

Each half-repeat, amino acids 1-67 and 68-134, has $n$ sequences. $S$ the treelength in nucleotide substitutions per codon. $\mathrm{dN} / \mathrm{dS}$ is the average $\omega$ estimated over sites and branches using a oneratio model.

$\omega$ and $\beta(p, q)$ are the parameters of the M8 beta distribution. $p 1$ is the estimated proportion of sites under positive selection. Sites predicted to be under selection are listed with posterior probabilities $\left({ }^{*} p<0.05,{ }^{* *} p<0.01\right)$. 
bindin and its egg surface receptor.

\section{Lectins and sperm-egg interaction}

A wealth of papers published over the past 40 years, investigating many different species, shows that the binding of sperm to eggs is often mediated by lectin-like molecular affinity interactions, where a carbohydrate on one gamete binds to a protein on the other gamete. Oyster bindin and mussel lysins have protein folds that resemble carbohydrate binding lectins. Mussel Lysin$\mathrm{M} 7$ resembles the carbohydrate recognition domain of C-type lectins (Springer and Crespi, 2007). The fold of oyster bindin is similar to the F-lectin family of fucose binding lectins. The most well known F-lectin is that of the European eel protein Anguilla anguillaagglutinin (AAA). The crystal structure of AAA shows that it has a unique protein fold representing a structurally novel family of lectins (Bianchet et al., 2002, Odom and Vasta, 2006). The Flectin domain of oyster sperm bindin is $45 \%$ similar to the consensus sequence of the F-lectin domain in the SMART database (smart00607). In addition, each tandem F-lectin repeat in oyster bindin has the three residues that are critical for fucose binding (Fig. 4; Bianchet et al., 2002).

Fucose lectin domains are ancient, members of this protein family are present in both prokaryotes and eukaryotes, but they are not found in amniotes (birds and mammals). Proteins with Flectin domains are common in the blood of fish and amphibia where they are thought to bind pathogenic bacteria as part of the innate immune system. Most proteins containing F-lectin domains are secreted and soluble, but oyster bindin is insoluble even in the high ionic strength of seawater at $\mathrm{pH} 8$. F-lectin domains are often found in tandem, possibly because multivalent binding increases the lectin affinity for its cognate ligand. For example, Xenopus laevis has a protein named Xla-PXN-FBPL that has five tandem F-lectin domains (Odom and Vasta, 2006). Monomeric alpha-D- and alpha-L-fucose do not block the agglutination of oyster oocytes by isolated acrosomal rings. This could be because multivalency of the fucose (a fucose polymer) is necessary to create high affinity binding between sperm bindin and its egg receptor. An alternate possibility is that the overwhelming positive charge of oyster bindin (isoelectric point 10.5) creates affinity for a suite of negatively charged egg surface molecules. Ligand binding does not always depend on multivalency and many examples of proteins with only a single F-lectin domain are known. For example, the AAA lectin has only one F-lectin domain that binds fucose residues present on bacterial lipopolysaccharides (Bianchet et al., 2002, Odom and Vasta, 2006).

\section{Why do oysters make so many different types of bindin?}

Combinatorial mechanisms of creating protein diversity are often found in biological recognition systems such as self-recognition or immune-recognition proteins (Litman etal., 2007, Shapiro 2007). However, no other gamete recognition protein has been found that uses combinatorial mechanisms to create such remarkable variation in its amino acid sequence. Why has oyster bindin evolved such a mechanism? Part of the answer to this question may lie in the molecular nature of the egg surface receptor for bindin. Identification and study of this receptor is our top priority. A complimentary hypothesis is that oysters evolved bindin variability as part of the mechanism to prevent polyspermy. Typically, many sperm compete for each egg, but fusion of more than one sperm causes abnormal development and death of the resulting zygote. This creates a conflict between sperm and egg at fertilization, and the eggs of different species have evolved a number of different strategies for avoiding the entry of multiple
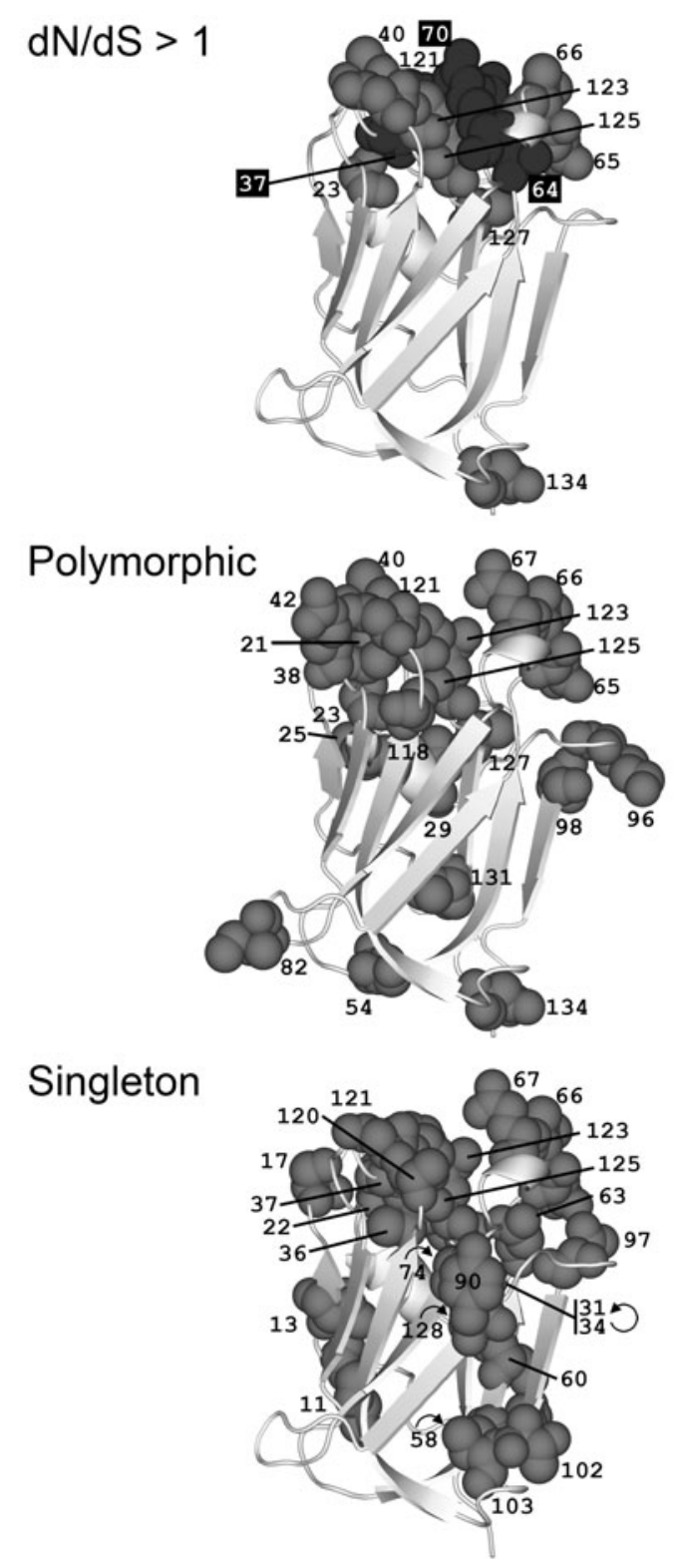

Fig. 8. Bindin F-lectin sequence threaded on the F-lectin crystal structure. The residues critical for fucose binding (H37, R64 and $\mathrm{R} 70$ ) are shown in black. The first frame shows the nine sites subjected to positive selection ( $d N / d S>1$ ) in grey mapped onto the alpha-carbon ribbon model of the F-lectin domain. Eight of the nine positively selected sites cluster around the fucose-binding region. The ninth site (134) is the last of each F-lectin repeat and differs between $C$-terminal clades that are spliced and those that are not spliced. The second frame shows polymorphic sites, those with amino-acid substitutions (from consensus) observed in two or more independent sequences. The third frame shows singleton substitutions, those observed only once in our data set. Polymorphic sites and singletons are not significantly spatially clustered. 
sperm.

Sea urchin eggs have a potent electrical "fertilization potential" that blocks fusion with a second sperm (Jaffe 1976). After fusion with the first sperm, egg membrane potential is reversed and cortical granule exocytosis occurs to create the fertilization envelope, a physical barrier that sperm cannot penetrate. Abalone eggs also have a strong reversal of the plasma membrane potential that blocks polyspermy (Stephano, 1992), however abalone eggs have no cortical granule reaction and there is no visible change in the egg vitelline envelope or egg surface following fertilization. These mechanisms allow sea urchin and abalone eggs to effectively prevent polyspermy, even at high sperm to egg ratios. Contrary to sea urchins and abalone, freshly spawned eggs of oysters are poor at preventing polyspermy. In experimental fertilizations, eggs can fuse with a second sperm for up to 15 minutes after fusion with the first sperm (Alliegro and Wright, 1983, Gould and Stephano, 2003, Stephano and Gould, 1988, Togo and Morisawa, 1999). Microelectrode experiments show that fresh $C$. gigas eggs do not have an electrical block to polyspermy (Gould and Stephano, 2003). Like abalone eggs, there are no visible changes on the oyster egg surface after fusion of the first sperm.

Oysters live in close proximity to each other and when they are gravid at least half the volume of a male can be sperm. Oyster eggs must often encounter multiple sperm at fertilization, but without a physical polyspermy block how do they avoid multiple insemination? One strategy that eggs could use to prevent polyspermy is to decrease the affinity of the sperm-egg bond to slow gamete fusion or exclude a subset of sperm. Females could accomplish this by making different forms of the bindin receptor that slightly mismatch with bindin to slow fertilization. At high sperm densities, eggs that are able to exclude some of the competing sperm would have lower rates of polyspermy (and therefore more surviving eggs) than those that cannot. Sperm competition favors exactly the opposite traits in males: sperm with bindins that increase rates of fertilization have an advantage. This general scenario has been described by sexual conflict theory (Rice and Holland, 1997). The optimal fertilization strategies of sperm and eggs are different and this sexual conflict creates the potential for a continuous evolutionary arms race between the gamete recognition proteins of sperm and eggs. At high sperm egg ratios, sperm competition selects for the fastest sperm to fuse, but eggs are selected to prevent polyspermy by having receptors that slow sperm fusion.

This conflict of interest exists whenever sperm from multiple males compete for eggs, but the resulting dynamics of molecular evolution are very different from species to species. Abalone typically have only a single lysin allele per species, sea urchins can have 10 or more bindin alleles, and oysters have many hundreds or thousands of bindin alleles per species. We suspect that these differences in the amount of male gamete recognition protein diversity resident within species result from the various ways that eggs exclude multiple sperm. Abalone and urchins rely primarily on global mechanisms that act over the entire egg surface, the electrical, cortical and physical blocks described above. Oysters lack these mechanisms and may avoid polyspermy using an alternate mechanism, by local recognition and rejection of individual sperm.

These different mechanisms, global and local sperm rejection, change the relative intensity of the competition between sperm and the conflict between sperm and eggs at fertilization. If oyster females are able to successfully diversify their receptors to avoid polyspermy, only a few of the sperm surrounding an oyster egg would be recognition compatible with it. The relative intensity of sperm competition in this situation is reduced relative to that of abalone, for example, where any of the sperm around an egg could potentially fertilize it. Mathematical models show that diversification of male traits to match female preferences tends to happen only when the relative intensity of sperm competition is low (Hayashi et al., 2007). In these conditions the benefit of specializing on a subset of the available female recognition types can outweigh the cost of reduced compatibility with remaining females. Selection causing male diversification can result in the separation of a single population into different mating groups, which could eventually become new species (Gavrilets and Hayashi, 2005, Hayashi et al., 2007). Patterns of intraspecific mate compatibility have been shown to depend on bindin polymorphisms in sea urchins, and the same process could maintain diversity in oyster bindin (Palumbi 1999, Levitan and Ferrell 2006).

\section{Prospects}

Our work on oyster bindin raises a series of interesting questions about the nature of bindin variability. First, how are the molecular mechanisms that create bindin diversity regulated and what is the functional effect of size variation? Each male has bindin cDNAs with 1 to 5 F-lectin repeats, but only one or two of these size variants are translated into protein and packaged in sperm acrosomes. We are currently working on the control regions and intron-exon structure of the genomic bindin sequence to determine if specific mRNA isoforms are selected for translation, or if bindin protein isoforms represent genomic allele size variation created by unequal crossing over. In either case, the functional consequences of bindin size variability are of interest given the importance of multivalency for binding affinity in other proteins with F-lectin domains.

Second, what is the extent of bindin variability within species, and how is this variability partitioned geographically and across speciation events? Within $C$. gigas, bindin has extraordinary size and sequence variability. Even after sequencing 39 full-length sequences with 107 repeats we continue to find new variants. Acrosomal proteins from the sperm of $C$. virginica react with the C. gigas anti-bindin. $C$. virginica individuals have bindin proteins of 48-63- and $75-\mathrm{kDa}$, so some size variability is retained across speciation events. Interestingly, $\boldsymbol{C}$. araikensis and $C$. sikamea sperm do not contain any proteins that react with the anti-bindin even though antibodies were made to the entire $C$. gigas $63-\mathrm{kDa}$ bindin protein. Shared bindin sequence polymorphism in $C$. gigas and $C$. virginicamay allow us to predict bindin polymorphisms that are likely to be involved in reproductive isolation between these species. Our samples of $C$. gigas are currently all from cultured individuals, but study of the distribution of polymorphisms across biogeographic clines in $C$. virginica should shed light on how bindin variability is distributed within natural populations (Hare and Avise 1996).

Third, what are the evolutionary processes that maintain bindin diversity within species, and what is the importance of this 
diversity in sperm-egg recognition at fertilization and in speciation? It is now clear that many reproductive proteins in many different species are subject to strong divergent selection. In general, conflicts of interest, similar in principle to the sexual conflict over polyspermy rate, are likely to be the cause of this broad evolutionary pattern. A related question asks about the selective mechanisms that cause reproductive incompatibility between closely related species. To answer this question we must study the very earliest stages of the process to determine which changes initiate reproductive isolation and which follow it.

Of particular interest is the identification and sequencing of the egg surface receptor for bindin. Existing egg receptors: the sea urchin egg bindin receptor (Kamei and Glabe, 2003) and the abalone egg lysin receptor VERL (Galindo et al., 2003), contain tandem repeats and have a history of positive selection between species. The polyspermy avoidance mechanism described above predicts that the bindin egg receptor will also be extraordinarily diverse. Once we determine the oyster egg receptor for bindin, it will be interesting to see what molecular mechanisms underlie receptor diversity and to examine the relationship between bindinreceptor interaction and sperm-egg compatibility within oyster populations.

\section{Acknowledgements}

GWM and VDV were supported by NIH Grant HD12986, SAS and WJS by NIH Grant HD42563, and NSF Grant DEB-0716761. SAS is a recipient of an NSERC PGSD International Graduate Fellowship. The locations of oyster culture facilities and the people who sent tissue for this study are noted in our original paper (Moy et al., 2008).

\section{References}

ALLIEGRO, M.C. and WRIGHT, D.A. (1983). Polyspermy inhibition in the oyster, Crassostrea virginica. J. Exp. Zool. 227: 127-37.

BIANCHET, M.A., ODOM, E.W., VASTA, G.R. and AMZEL, L.M. (2002). A novel fucose recognition fold involved in innate immunity. Nat. Struct. Biol. 9: 628-34.

BIERMANN, C.H. (1998). The molecular evolution of sperm bindin in six species of sea urchin (Echinoida: Strongylocentrotidae). Mol. Biol. Evol. 15:1761-71.

BORASTON, A.B., WANG, D. and BURKE, R.D. (2006). Blood group antigen recognition by a Streptococcus pneumoniae virulence factor. J. Biol. Chem. 281: 35263-71.

BRANDRIFF, B., MOY, G.W. and VACQUIER, V.D. (1978). Isolation of sperm bindin from the oyster Crassostrea gigas. Gamete Res. 1:89-99.

CLARK, N.L., FINDLAY, G.D., YI, X., MACCOSS, M.J. and SWANSON, W.J. (2007). Duplication and selection on abalone sperm lysin in an allopatric population. Mol. Biol. Evol. 24:2081-90.

EIRIN-LOPEZ, J.M., LEWIS, J.D., HOWE LE, A. and AUSIO, J. (2006). Common phylogenetic origin of protamine-like (PL) proteins and histone $\mathrm{H} 1$ : evidence from bivalve PL genes. Mol. Biol. Evol. 23: 1304-17.

GALINDO, B.E., VACQUIER, V.D. and SWANSON, W.J. (2003). Positive selection in the egg receptor for abalone sperm lysin. Proc. Natl. Acad. Sci. USA 100: 4639-43.

GAVRILETS, S. (2000). Rapid evolution of reproductive barriers driven by sexual conflict. Nature 403: 886-9.

GAVRILETS, S. and HAYASHI, T.I. (2005). Speciation and sexual conflict. Evol. ECol. 19:167-98.

GAVRILETS, S. and WAXMAN, D. (2002). Sympatric speciation by sexual conflict. Proc. Natl. Acad. Sci. USA 99: 10533-8.

GLABE, C.G. and VACQUIER, V.D. (1977). Species-specific agglutination of eggs by bindin isolated from sea urchin sperm. Nature 267:836-838.

GOULD, M.C. and STEPHANO, J.L. (2003). Polyspermy prevention in marine invertebrates. Microsc. Res. Tech. 61: 379-88.

HARE, M. P. and AVISE J. C. (1996). Molecular genetic analysis of a stepped multilocus cline in the American oyster (Crassostrea virginica). Evolution 50:2305-2315.

HAYASHI, T.I., VOSE, M. and GAVRILETS, S. (2007). Genetic differentiation by sexual conflict. Evolution Int. J. Org. Evolution 61: 516-29.

HAYGOOD, R. (2004). Sexual conflict and protein polymorphism. Evolution Int. J. Org. Evolution 58: 1414-23.

HYLANDER, B.L. and SUMMERS, R.G. (1977). An ultrastructural analysis of the gametes and early fertilization in two bivalve molluscs, Chama macerophylla and Spisula solidissima with special reference to gamete binding. Cell Tissue Res. 182: 469-89.

JAFFE, L.A. (1976). Fast block to polyspermy in sea urchin eggs is electrically mediated. Nature 261:68-71.

KAMEI, N. and GLABE, C.G. (2003). The species-specific egg receptor for sea urchin sperm adhesion is EBR1, a novel ADAMTS protein. Genes Dev.17: 2502-7.

KOSAKOVSKY POND, S.L., POSADA, D., GRAVENOR, M.B., WOELK, C.H. and FROST, S.D. (2006). Automated phylogenetic detection of recombination using a genetic algorithm. Mol. Biol. Evol. 23: 1891-901.

KRESGE, N., VACQUIER, V.D. and STOUT, C.D. (2001). Abalone lysin: the dissolving and evolving sperm protein. BioEssays 23: 95-103.

LAMBERT, C., LEONARD, N., DE BOLLE, X. and DEPIEREUX, E. (2002). ESyPred3D: prediction of proteins 3D structures. Bioinformatics 18: 1250-6.

LANDRY, C., GEYER, L.B., ARAKAKI, Y., UEHARA, T. and PALUMBI, S.R. (2003). Recent speciation in the Indo-West Pacific: rapid evolution of gamete recognition and sperm morphology in cryptic species of sea urchin. Proc. Roy. Soc. Lond. B. Biol. Sci. 270: 1839-47.

LEVITAN, D.R. and FERRELL, D.L. (2006). Selection on gamete recognition proteins depends on sex, density, and genotype frequency. Science 312: 2679 .

LEVITAN, D.R., TERHORST, C.P. and FOGARTY, N.D. (2007). The risk of polyspermy in three congeneric sea urchins and its implications for gametic incompatibility and reproductive isolation. Evolution Int. J. Org. Evolution 61: 2007-14.

LITMAN, G. W., DISHAW, L. J., CANNON, J. P., HAIRE, R. N. and RAST, J. P. (2007) Alternative mechanisms of immune receptor diversity Curr Opin Immunol. 19:526-534.

MCCARTNEY, M.A. and LESSIOS, H.A. (2004). Adaptive evolution of sperm bindin tracks egg incompatibility in neotropical sea urchins of the genus Echinometra. Mol. Biol. Evol. 21: 732-45.

METZ, E.C., GOMEZ-GUTIERREZ, G. and VACQUIER, V.D. (1998a). Mitochondrial DNA and bindin gene sequence evolution among allopatric species of the sea urchin genus Arbacia. Mol. Biol. Evol.15:185-95.

METZ, E.C. and PALUMBI, S.R. (1996). Positive selection and sequence rearrangements generate extensive polymorphism in the gamete recognition protein bindin. Mol. Biol. Evol. 13: 397-406.

METZ, E.C., ROBLES-SIKISAKA, R. and VACQUIER, V.D. (1998b). Nonsynonymous substitution in abalone sperm fertilization genes exceeds substitution in introns and mitochondrial DNA. Proc. Natl. Acad. Sci. USA 95: 10676-81.

METZ, E.C. KANE, R.E., YANAGIMACHI, H. and PALUMBI, S.R. (1994). Fertilization between closely related sea urchins is blocked by incompatibilities during sperm-egg attachment and the early stages of fusion. Biol. Bull. 187:23-34.

MOY, G.W., SPRINGER, S.A., ADAMS, S.L., SWANSON, W.J. and VACQUIER, V.D. (2008). Extraordinary intra-specific diversity in oyster sperm bindin. Proc. Natl. Acad. Sci. U.S.A. In Press.

ODOM, E.W. and VASTA, G.R. (2006). Characterization of a binary tandem domain F-type lectin from striped bass (Morone saxatilis). J. Biol. Chem. 281: 1698-713.

PALUMBI, S.R. (1992). Marine speciation on a small planet. Trends Ecol. Evol. 7:114-8.

PALUMBI, S.R. (1999). All males are not created equal: fertility differences depend on gamete recognition polymorphisms in sea urchins. Proc. Natl. Acad. Sci. USA 96: $12632-7$.

PALUMBI, S.R. and METZ, E.C. (1991). Strong reproductive isolation between 


\section{S.A. Springer et al.}

closely related tropical sea urchins (genus Echinometra). Mol. Biol. Evol. 8:22739.

RICE, W.R. and HOLLAND, B. (1997). The enemies within: intergenomic conflict. Interlocus contest evolution, ICE and the intraspecific red queen. Behav. Ecol. Sociobiol. 41:1-10.

RIGINOS, C. and MCDONALD, J.H. (2003). Positive selection on an acrosomal sperm protein, M7 lysin, in three species of the mussel genus Mytilus. Mol. Biol. Evol. 20: 200-7.

RIGINOS, C., WANG, D. and ABRAMS, A.J. (2006). Geographic variation and positive selection on M7 lysin, an acrosomal sperm protein in mussels (Mytilus spp.). Mol. Biol. Evol. 23: 1952-65.

SHAPIRO, L. (2007). Self-recognition at the atomic Level: understanding the astonishing molecular diversity of homophilic Dscams. Neuron 56: 10-13.

SPRINGER, S.A. and CRESPI, B.J. (2007). Adaptive gamete-recognition divergence in a hybridizing Mytilus population. Evolution Int. J. Org. Evolution 61: 772-83.

STEPHANO, J.L. (1992). A study of polyspermy in abalone. In: Shepard, S.A. Tegner, M.J. and Guzman-del-Proo, S. (eds). Abalone Fisheries, Biology and Culture. Fishing News Books, Cambridge, U.K. p518-528.

STEPHANO, J.L. and GOULD, M. (1988). Avoiding polyspermy in the oyster (Crassostrea gigas). Aquaculture 73:295-307.

SWANSON, W.J. and VACQUIER, V.D. (1995a). Extraordinary divergence and positive Darwinian selection in a fusagenic protein coating the acrosomal process of abalone spermatozoa. Proc. Natl. Acad. Sci. USA 92: 4957-61.

SWANSON, W.J. and VACQUIER, V.D. (1995b). Liposome fusion induced by a Mr 18,000 protein localized to the acrosomal region of acrosome reacted abalone spermatozoa. Biochemistry 34:14202-08.

SWANSON, W.J. and VACQUIER, V.D. (1997). The abalone egg vitelline envelope receptor for sperm lysin is a giant multivalent molecule. Proc. Nat/. Acad. Sci. USA 94: 6724-9.

SWANSON, W.J. and VACQUIER, V.D. (1998). Concerted evolution in an egg receptor for a rapidly evolving abalone sperm protein. Science 281:710-12.

SWANSON, W.J. and VACQUIER, V.D. (2002). The rapid evolution of reproductive proteins. Nat. Rev. Genet. 3: 137-44.

SWOFFORD, D.L. (1998). PAUP*. Phylogenetic analysis using parsimony ( ${ }^{*}$ and other methods) Version 4. Sinauer Associates, Sunderland, MA.

TOGO, T. and MORISAWA, M. (1999). Mechanisms for blocking polyspermy in oocytes of the oyster Crassostrea gigas. J. Exp. Zool. 283:307-14

VACQUIER V.D. (1998). Evolution of gamete recognition proteins. Science281:19951998.

VACQUIER, V.D., SWANSON, W.J., and HELLBERG, M.E. (1995). What have we learned about sea urchin sperm bindin? Dev. Growth \& Differ. 37:1-10.

YANG, Z. (1997). PAML: a program package for phylogenetic analysis by maximum likelihood. Comput. Appl. Biosci. 13: 555-6.

ZIGLER, K.S. and LESSIOS, H.A. (2003a). 250 million years of bindin evolution. Biol. Bull. 205: 8-15.

ZIGLER, K.S. and LESSIOS, H.A. (2003b). Evolution of bindin in the pantropical sea urchin Tripneustes: comparisons to bindin of other genera. Mol. Biol. Evol. 20: $220-31$.

ZIGLER, K.S. and LESSIOS, H.A. (2004). Speciation on the coasts of the new world: phylogeography and the evolution of bindin in the sea urchin genus'Lytechinus. Evolution Int. J. Org. Evolution 58: 1225-41.

ZIGLER, K.S., MCCARTNEY, M.A., LEVITAN, D.R. and LESSIOS, H.A. (2005). Sea urchin bindin divergence predicts gamete compatibility. Evolution Int. J. Org. Evolution 59:2399-404. 


\section{Related, previously published Int. J. Dev. Biol. articles}

See our recent Special Issue Developmental Biology in Poland edited by Tarkowski, Maleszewski and Kloc at: http://www.ijdb.ehu.es/web/contents.php?vol=52\&issue=2-3

See our recent Special Issue Ear Development edited by Fernando Giraldez and Bernd Fritzsch at: http://www.ijdb.ehu.es/web/contents.php?vol=51\&issue=6-7

Key apoptosis regulating proteins are down-regulated during postnatal tissue development Shane D. Madden, Maryanne Donovan and Thomas G. Cotter Int. J. Dev. Biol. (2007) 51: 415-424

Embryonic stem cells differentiate into insulin-producing cells without selection of nestin-expressing cells Przemyslaw Blyszczuk, Christian Asbrand, Aldo Rozzo, Gabriela Kania, Luc St-Onge, Marjan Rupnik and Anna M. Wobus Int. J. Dev. Biol. (2004) 48: 1095-1104

The generation of insulin-producing cells from embryonic stem cells - a discussion of controversial findings Gabriela Kania, Przemyslaw Blyszczuk and Anna M. Wobus

Int. J. Dev. Biol. (2004) 48: 1061-1064

A P19CI6 GFP reporter line to quantify cardiomyocyte differentiation of stem cells. Jennifer C Moore, Rene Spijker, Anton C Martens, Teun de Boer, Martin B Rook, Marcel A G van der Heyden, Leon G Tertoolen and Christine L Mummery

Int. J. Dev. Biol. (2004) 48: 47-55

X-epilectin: a novel epidermal fucolectin regulated by BMP signalling Karine Massé, Rebecca Baldwin, Mark W. Barnett and Elizabeth A. Jones Int. J. Dev. Biol. (2004) 48: 1119-1129

Sperm-egg interaction at fertilization: glycans as recognition signals.

F Rosati, A Capone, C D Giovampaola, C Brettoni and R Focarelli

Int. J. Dev. Biol. (2000) 44: 609-618

Student-oriented learning: an inquiry-based developmental biology lecture course. George M Malacinski

Int. J. Dev. Biol. (2003) 47: 135-140

Egg-jelly signal molecules for triggering the acrosome reaction in starfish spermatozoa. M Hoshi, T Nishigaki, A Ushiyama, T Okinaga, K Chiba and M Matsumoto Int. J. Dev. Biol. (1994) 38: 167-174

Cellular origin of the basement membrane in embryonic chicken/quail chimeras. F Harrisson

Int. J. Dev. Biol. (1993) 37: 337-347

Release from the metaphase I block in invertebrate oocytes: possible involvement of $\mathrm{Ca}$ +/calmodulin-dependent kinase III.

H Abdelmajid, C Leclerc-David, M Moreau, P Guerrier and A Ryazanov Int. J. Dev. Biol. (1993) 37: 279-290

The oocyte lamin persists as a single major component of the nuclear lamina during embryonic development of the surf clam.

G Dessev and R Goldman

Int. J. Dev. Biol. (1990) 34: 267-274

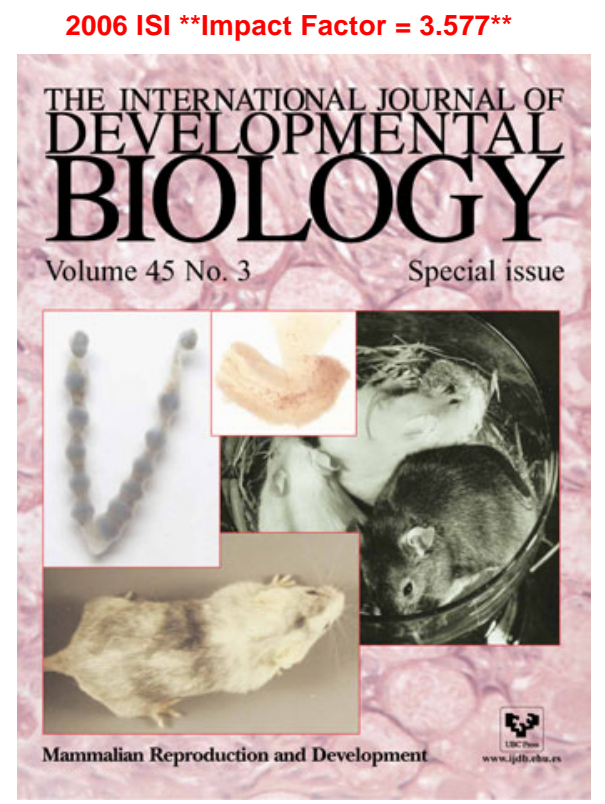

